\title{
THREE-DIMENSIONAL DIGITAL DOCUMENTATION OF HERITAGE SITES USING TERRESTRIAL LASER SCANNING AND UNMANNED AERIAL VEHICLE PHOTOGRAMMETRY
}

\author{
Y. H. Jo * J.Y. Kim \\ Dept. of Cultural Heritage Conservation Sciences, Kongju National University, 32588, Republic of Korea \\ (joyh, jiyoung1995)@kongju.ac.kr
}

\begin{abstract}
KEY WORDS: Terrestrial Laser Scanning, Unmanned Aerial Vehicle Photogrammetry, Three-dimensional Digital Documentation, Cultural Heritage Sites
\end{abstract}

\begin{abstract}
:
Three-dimensional digital documentation is an important technique for the maintenance and monitoring of cultural heritage sites. This study focuses on the three-dimensional digital documentation of the Magoksa Temple, Republic of Korea, using a combination of terrestrial laser scanning and unmanned aerial vehicle (UAV) photogrammetry. Terrestrial laser scanning mostly acquired the vertical geometry of the buildings. In addition, the digital orthoimage produced by UAV photogrammetry had higher horizontal data acquisition rate than that produced by terrestrial laser scanning. Thus, the scanning and UAV photogrammetry were merged by matching 20 corresponding points and an absolute coordinate system was established using seven ground control points. The final, complete threedimensional shape had perfect horizontal and vertical geometries. This study demonstrates the potential of integrating terrestrial laser scanning and UAV photogrammetry for three-dimensional digital documentation. This new technique is expected to contribute to the three-dimensional digital documentation and spatial analysis of cultural heritage sites.
\end{abstract}

\section{INTRODUCTION}

Three-dimensional terrestrial laser scanning and photogrammetry are considered to be digital documentation techniques because they create a digital model that is nearly identical to the physical geometry based on measured data (Herráez et al., 2016; Galantucci, 2015). Terrestrial laser scanning measures the threedimensional spatial information of an object within a certain distance from the ground using a laser (Rüther et al., 2009; Fabbri et al., 2017). This method can quickly acquire the geometry of a large cultural heritage site because of its high operation speed, mobility, and accessibility. The accuracy and data acquisition rate for terrestrial laser scanning are highest in the vertical direction.

Another method, unmanned aerial vehicle (UAV) photogrammetry, provides some advantages compared with laser scanning (Fernández-Lozano and Gutiérrez-Alonso, 2016). The orthoimage created via UAV photogrammetry allows distances, angles, plane coordinates, and areas to be directly measured on the orthoimage because the relations between locations are identical to those on the topographic map (Watanabe and Kawahara, 2016). In particular, UAV photogrammetry has higher horizontal positional accuracy and data acquisition rate than terrestrial laser scanning. Therefore, if terrestrial laser scanning and UAV photogrammetry technologies are properly integrated, multidirectional numerical information along with the plane arrangements of architectural heritage sites can be acquired (Assali et al., 2014; Yang et al., 2015).

This study applied terrestrial laser scanning and UAV photogrammetry to the three-dimensional digital documentation of Magoksa Temple in Gongju, a representative temple of the Republic of Korea. Point clouds of the temple obtained from two methods were integrated, and the orthoimage and threedimensional modeling were acquired using specialized software. The results of this study are expected to contribute to the threedimensional documentation and spatial analysis of heritage sites.

\section{STUDY AREA}

The Magoksa Temple is divided into north and south territories based on a central stream, as shown in Figure 1. The two territories have horizontal and vertical arrangements, respectively. The north territory primarily contains Daeungbojeon Hall (Korean Treasure No. 801), Daegwanbojeon Hall (Korean Treasure No. 802), and Five-Story Stone Pagoda (Korean Treasure No. 799). The main heritage site of the south territory is Yeongsanjeon Hall (Korean Treasure No. 800).

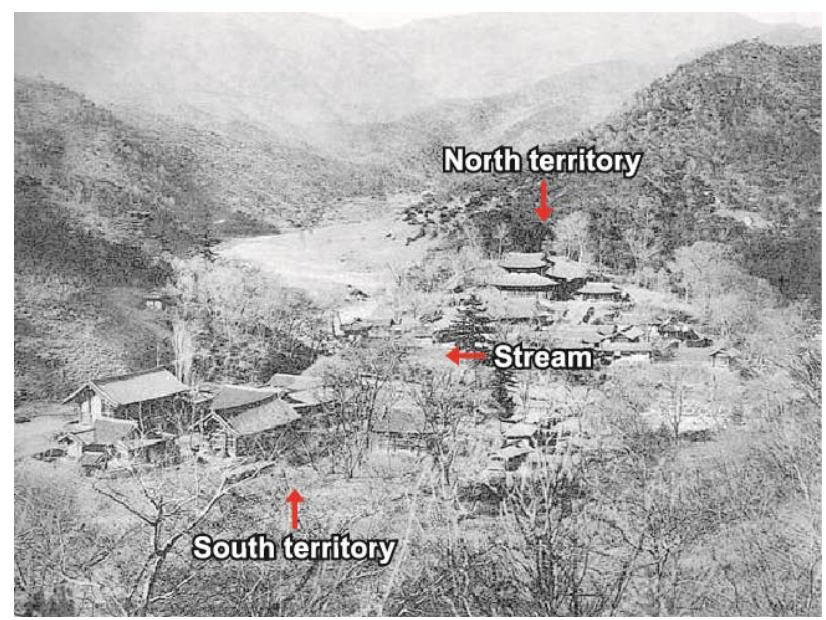

Figure 1. Magoksa Temple in the 1920s, as documented in the Joseon Historical Remains Pictorial Book

\section{EQUIPMENT AND SOFTWARE}

Terrestrial laser scanner (Leica, ScanStation C10) used to create the three-dimensional modeling of the Magoksa Temple is based on laser pulse time of flight (Figure 2a). The laser light pulse is projected on a surface, and the reflected beam is collected by the scanner's sensor. The laser's time of flight between emission and 
reception provides three-dimensional geometric information on the object's surface. The scanner used for this study has a maximum scan speed of 50,000 points per second and accuracies of $6 \mathrm{~mm}$ (position) and $4 \mathrm{~mm}$ (distance). A specialized external camera with a fisheye lens (SIGMA, 8-mm F3.5 EX DG Circular FISHEYE) was used as the texture mapping source. The scanned point cloud data were post-processed using the Cyclone 8.0.3 software.

UAV photogrammetry was conducted using a rotorcraft UAV (Leica, Aibot X6) and post-processing software (Agisoft, PhotoScan Professional). The UAV used is a high-performance hexacopter with stable and automatic flight performance (Figure 2b). Moreover, it has various sensors, including GPS, a gyroscope, ultrasonic transducer, and a smart camera system. The photogrammetry software allows professional three-dimensional modeling using aerial photographs. The photographs are automatically processed by the software to produce a threedimensional reconstruction.
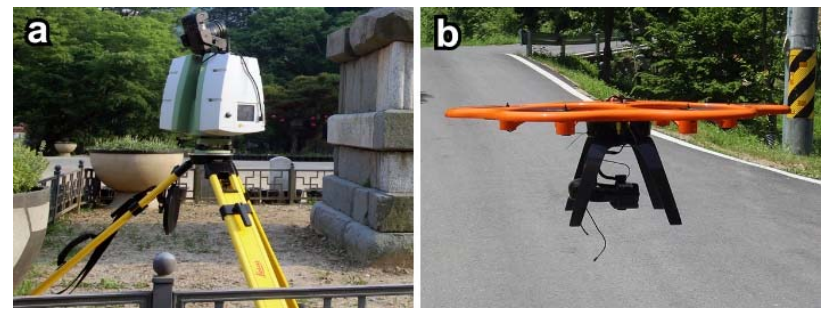

Figure 2. Equipment used for scanning and photogrammetry: (a) Terrestrial laser scanner with specialized external camera; (b) Hexacopter UAV

\section{RESULTS}

\subsection{Terrestrial laser scanning}

The most important consideration in the field scan is to select a scan position for the object of interest. In this study, the field scan was performed from 82 positions in consideration of various factors such as measurable range and overlap because the Magoksa Temple is fairly wide (Figure 3). In addition, the stone pagoda, a key part of the heritage site, was scanned from 24 positions by dividing the pagoda into lower and upper sections based on its height.

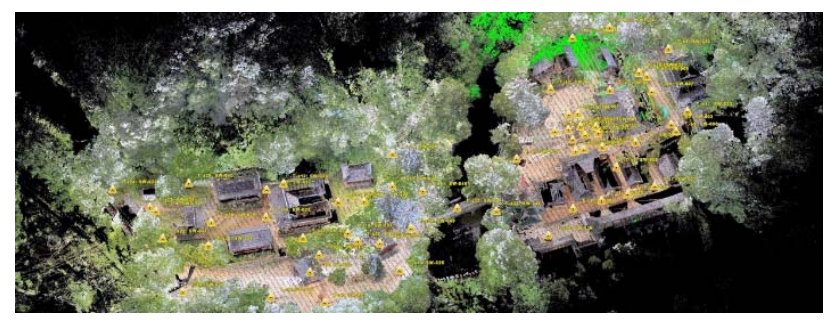

Figure 3. Field scan positions for the Magoksa Temple

The three-dimensional shape of the temple was generated by registering, merging, and noise filtering the scanning data. Shape registering was conducted by selecting at least three corresponding points from each point cloud. Subsequently, all registered point clouds were merged and filtered to complete one object model. Figure 4 shows the point cloud and texture mapping images of the Magoksa Temple obtained by merging and filtering the laser scanning data. Notably, the overall threedimensional shape reflected the vertical geometry of the building; however, high-level horizontal coordinates (e.g., the geometry of the roof) were not well-acquired.
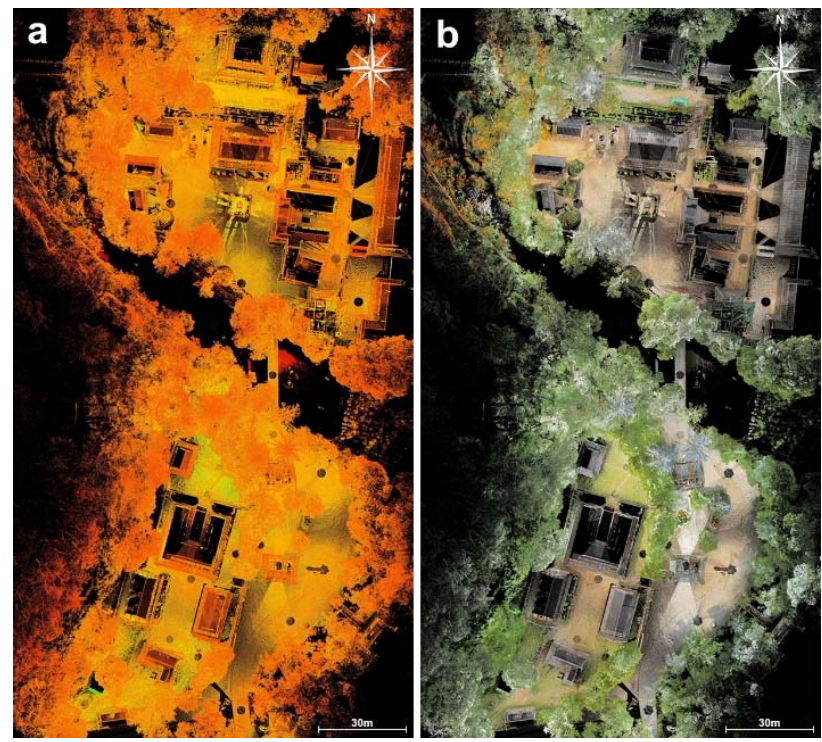

Figure 4. Orthoimage of the Magoksa Temple created by terrestrial laser scanning: (a) Point cloud image; (b) Texture mapping image

\subsection{UAV photogrammetry}

Two UAV flight plans were set for the south and north territories of the Magoksa Temple (Figures 5a, 5b). The flight ranges (approximately $250 \times 400 \mathrm{~m}$ ) and paths were then established on the satellite map using specialized software, and the following conditions of flight operation were input into the software: vertical camera angle; altitude $=80 \mathrm{~m}$; overlap $=80 \%$; sidelap $=$ $60 \%$; flight speed $=3 \mathrm{~m} / \mathrm{s}$; and flight time $=20 \mathrm{~min}$.
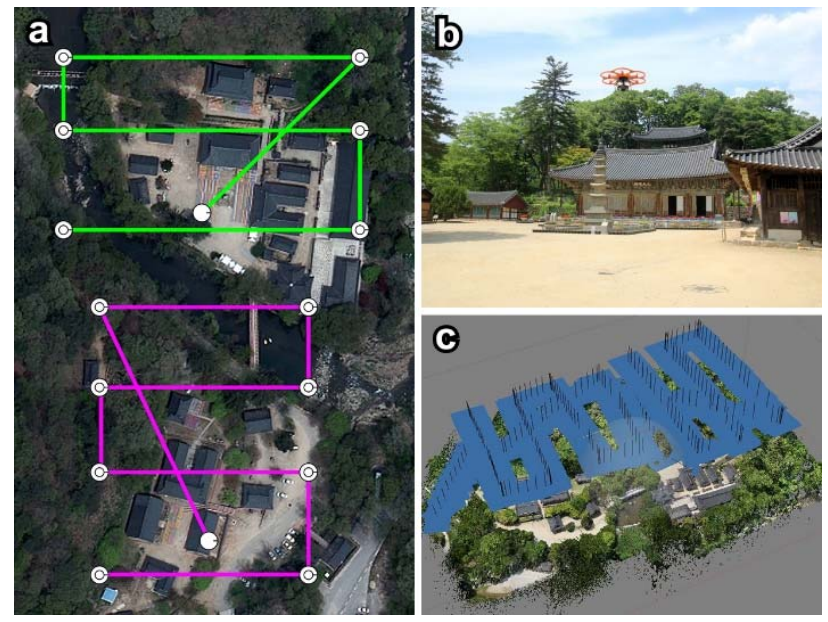

Figure 5. Process of UAV photogrammetry used to map the Magoksa Temple: (a) Flight plan; (b) Image of the flying UAV; (c) Photography positions

Image processing involved arranging photographs, extracting point clouds, creating meshes, and mapping textures. First, 213 still photographs obtained by the UAV camera were arranged based on the shooting sequences, and the coordinates in the photographs were registered (Figure 5c). The interior and exterior orientation parameters of the cameras were then established. Finally, the orthoimage was completed by generating 
a mesh and mapping texture. As shown in Figure 6, the accuracy and data acquisition rate for UAV photogrammetry were higher in the horizontal direction.
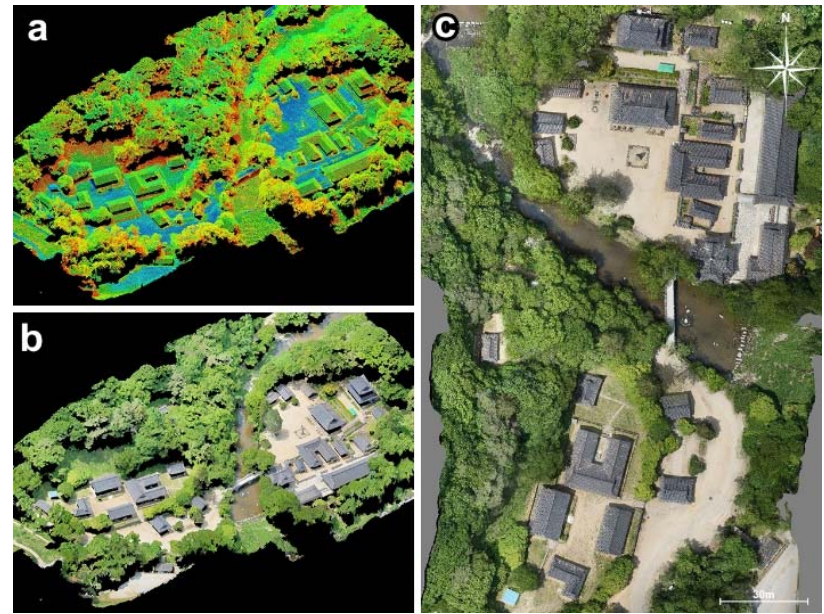

Figure 6. UAV photogrammetry results for the Magoksa Temple: (a) Point cloud data; (b) Texture mapping image; (c) Orthoimage

\subsection{Integrated three-dimensional modeling}

We constructed a three-dimensional modeling of the Magoksa Temple by merging the vertical point clouds from laser scanning and the horizontal orthoimage from UAV photogrammetry. The scanning point clouds had a relative coordinate system, whereas the UAV photographs were tagged with GPS information. Accordingly, the scanning point clouds were converted to an absolute coordinate system based on ground control points to increase the accuracy and reliability of the topographical survey.
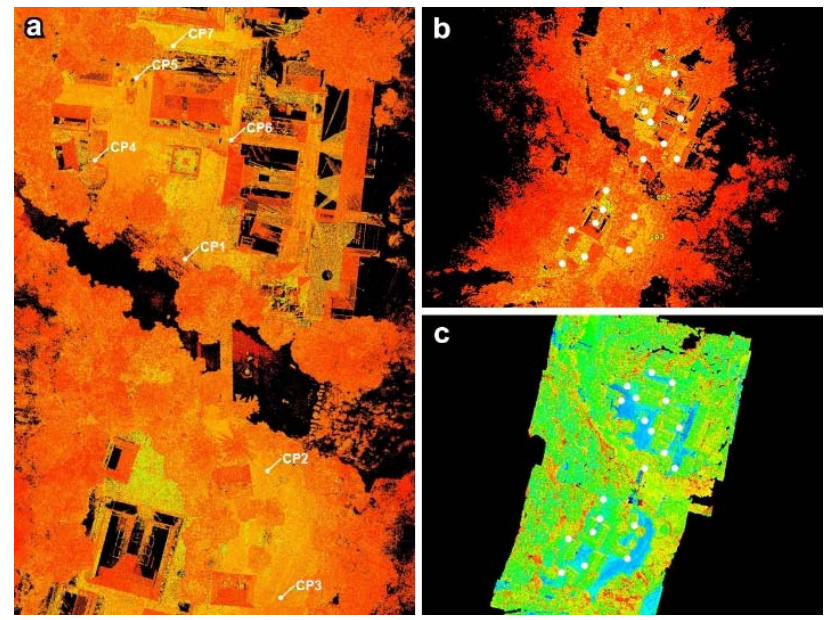

Figure 7. Three-dimensional modeling of the Magoksa Temple:

(a) Seven ground control points; (b) Registration points of the terrestrial scanning; (c) Point clouds extracted from UAV photogrammetry result

First, seven ground control points were surveyed using the RTK GPS system, and differential leveling was carried out. The ground control points were then input into the scanning results (Figure 7a) to obtain three-dimensional data in the absolute coordinate system. Subsequently, shape registering and merging were performed by matching 20 corresponding points between the scanning and photogrammetry results (Figure $7 \mathrm{~b}, 7 \mathrm{c}$ ). The completed three-dimensional shape had perfect horizontal and vertical geometries (Figure 8). As shown in Figure 9, the Magoksa Temple has east-west and south-north lengths of approximately 100 and $230 \mathrm{~m}$, respectively, and the temple is located between 100 and $130 \mathrm{~m}$ above sea level.

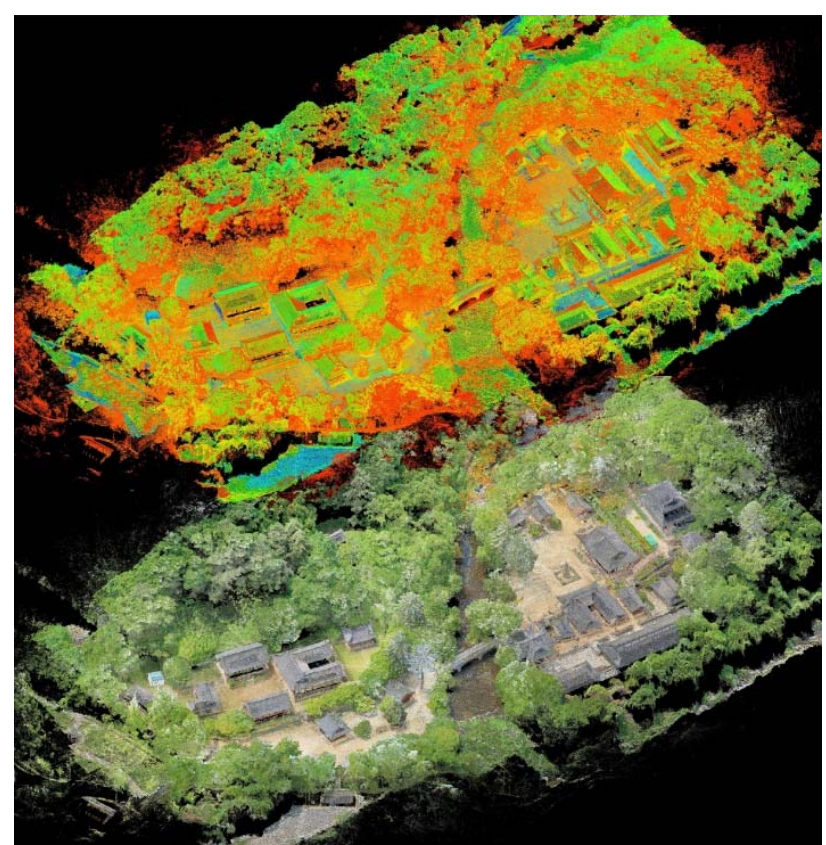

Figure 8. Integrated terrestrial laser scanning and UAV photogrammetry results

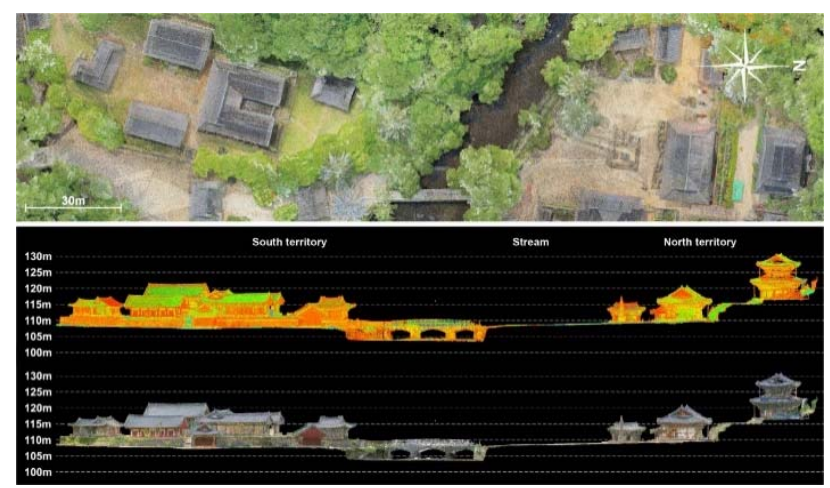

Figure 9. Cross section of the terrain of the Magoksa Temple

\section{DISCUSSION AND CONCLUSION}

This study focused on the three-dimensional digital documentation of the Magoksa Temple. Two digital techniques, terrestrial laser scanning, and UAV photogrammetry, were applied to acquire multidirectional numerical information on the temple. Overall, the scanning and UAV photogrammetry showed high accuracy and data acquisition rates in both the vertical and horizontal directions.

Integrated three-dimensional modeling using both terrestrial scanning and UAV photogrammetry is a useful digital documentation technology for spatial analysis. This integrated method is expected to contribute to the three-dimensional digital documentation of cultural heritage sites and individual monuments. However, this study has not been numerically verified integration errors between the scanning and UAV photogrammetry results. The vertical and horizontal positional accuracies should be studied in depth in order to fully utilize the 
orthoimage and three-dimensional modeling as digital topographic maps.

\section{ACKNOWLEDGEMENTS}

This research was supported by Basic Science Research Program through the National Research Foundation of Korean(NRF) funded by the Ministry of Science, ICT \& Future Planning(NRF2016R1C1B2010883).

\section{REFERENCES}

Assali, P., Grussenmeyer, P., Villemin, T., Pollet, N., Viguier, F., 2014, Surveying and modeling of rock discontinuities by terrestrial laser scanning and photogrammetry: Semi-automatic approaches for linear outcrop inspection. Journal of Structural Geology, 66, 102-114.

Fabbri, S., Sauro, F., Santagata, T., Rossi, G., Waele, J.D., 2017, High-resolution 3-D mapping using terrestrial laser scanning as a tool for geomorphological and speleogenetical studies in caves: An example from the Lessini mountains (North Italy). Geomorphology, 280, 16-29.

Fernández-Lozano, J., Gutiérrez-Alonso, G., 2016, Improving archaeological prospection using localized UAVs assisted photogrammetry: An example from the Roman Gold District of the Eria River Valley (NW Spain). Journal of Archaeological Science: Reports 5, 509-520.

Galantucci, L.M., Pesce, M., Lavecchia, F., 2015, A stereo photogrammetry scanning methodology, for precise and accurate 3D digitization of small parts with sub-millimeter sized features. CIRP Annals - Manufacturing Technology, 64, 507-510.

Herráez, J., Martínez, J.C., Coll, E., Martín, M.T., Rodríguez, J., 2016, 3D modeling by means of videogrammetry and laser scanners for reverse engineering. Measurement, 87, 216-227.

Rüther, H., Chazan, M., Schroeder, R., Neeser, R., Held, C., Walker, S.J., Matmon, A., Horwitz, L.K., 2009, Laser r scanning for conservation and research of African cultural heritage sites: the case study of Wonderwerk Cave, South Africa. Journal of Archaeological Science, 36, 1847-1856.

Watanabe, Y., Kawahara, Y., 2016, UAV photogrammetry for monitoring changes in river topography and vegetation. Procedia Engineering, 154, 317-325.

Yang, B., Zang, Y., Dong, Z., and Huang, R., 2015, An automated method to register airborne and terrestrial laser scanning. ISPRS Journal of Photogrammetry and Remote Sensing, 109, 62-76. 